Document downloaded from:

http://hdl.handle.net/10251/103736

This paper must be cited as:

Guardiola, C.; Olmeda, P.; Pla Moreno, B.; Bares-Moreno, P. (2017). In-cylinder pressure based model for exhaust temperature estimation in internal combustion engines. Applied Thermal Engineering. 115:212-220. doi:10.1016/j.applthermaleng.2016.12.092

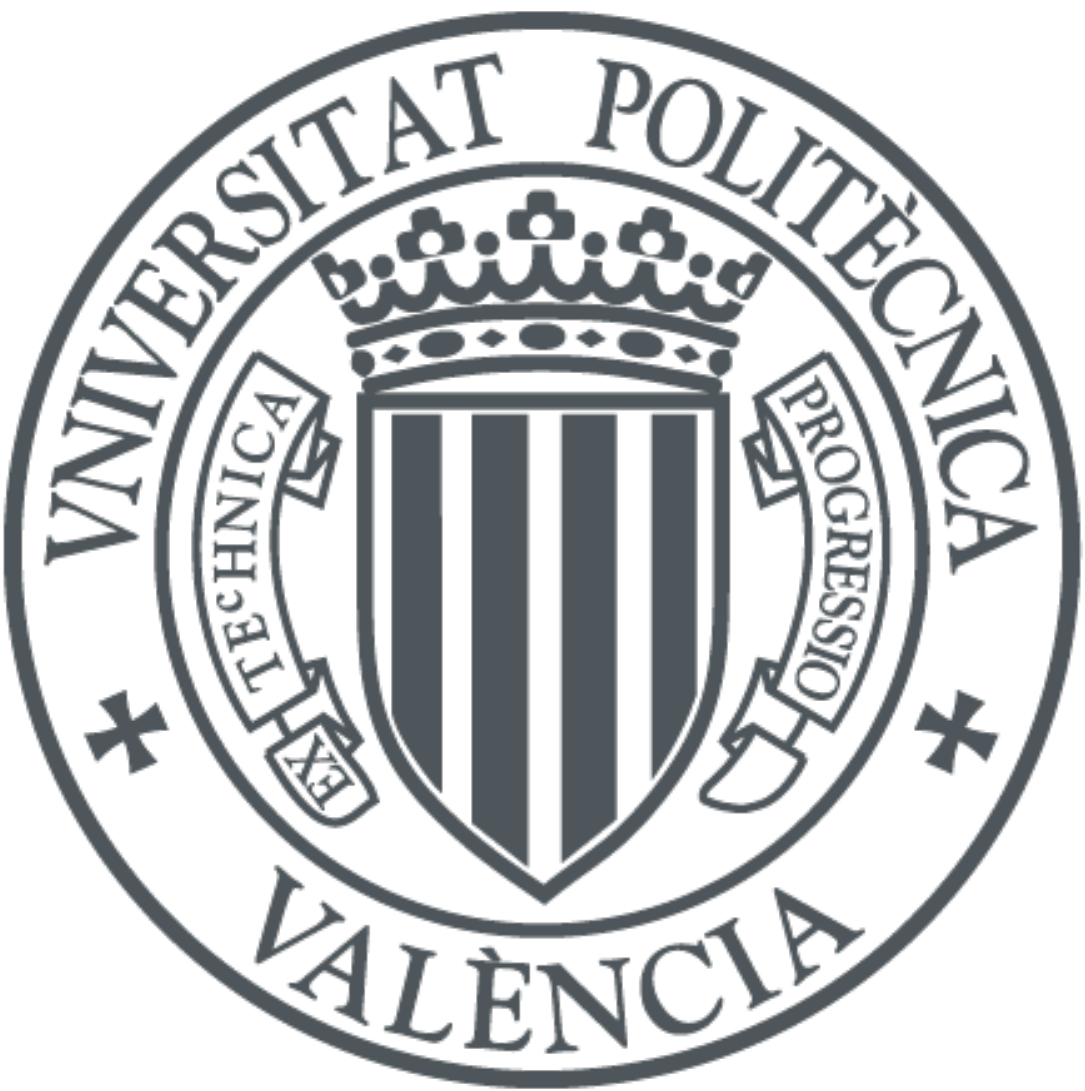

The final publication is available at

http://dx.doi.org/10.1016/j.applthermaleng.2016.12.092

Copyright Elsevier

Additional Information 


\title{
In-cylinder pressure based model for exhaust temperature estimation in internal combustion engines
}

\author{
C. Guardiola, P. Olmeda, B. Pla and P. Bares \\ CMT-Motores Térmicos, Universitat Politècnica de València, Valencia, Spain.
}

\begin{abstract}
Exhaust temperature is a valuable parameter for engine control. However, measurement conditions at the engine exhaust and the slow dynamic response of temperature sensors difficult the determination of the instantaneous exhaust temperature. The present paper proposes a methodology for estimating the exhaust temperature exclusively relying in-cylinder pressure signal, engine speed and exhaust lambda.The presented methodology can replace or actualize widespread look-up table models for correcting calibration offsets, due to ageing, sensor bias or disturbances associated with the engine operation. The method uses the existence of resonant modes in the in-cylinder pressure for inferring the trapped mass and the in-cylinder temperature. An isentropic expansion of the gasses through the valves is assumed for estimating the cylinder outlet temperature of the gases, and the gas temperature drop along the exhaust runner and manifold is modelled through a nodal thermal model. The method was compared with current models under steady and transient conditions in a four stroke CI engine. Variations of injection, EGR, intake pressure and rail pressure were performed under steady operation and the transient response of the method was validated under specific transient test and at the WLTP cycle. A time invariant first order model was used for comparing the estimated temperature with that provided by the experimental sensors.
\end{abstract}

Keywords: Internal combustion engines, temperature, measurement, estimation, in-cylinder pressure, models, virtual sensors, exhaust 


\section{Introduction}

Combustion engine control is increasing in complexity as new stringent regulations are forcing Compression Ignited (CI) engines to lower pollutant emissions, while customers demand improved performance and fuel economy.

5 Models and sensors are being included in Electronic Control Units (ECU) to replace look-up tables and improve precision and transient response.

Exhaust temperature is an important parameter for engine control: an accurate and fast estimation of the exhaust gases temperature permits maintaining non-damaging exhaust conditions [1]; turbocharger and after-treatment systems control and optimization require from an exhaust temperature measurement or estimation $[2,3,4]$, since turbine available power and catalyst light-off strongly depends on temperature; and finally, Exhaust Gas Recirculation (EGR) rate observers and models rely on exhaust gases temperature to estimate its value $[5,6]$.

Unfortunately, instantaneous estimation of exhaust temperature is highly challenging and requires from models in order to compensate the slow time response of temperature sensors [7]. Moreover, three-dimensional non-homogeneity of the exhaust temperature [8], together with the existence of pulsating conditions at the exhaust manifold [9], complicate both the measurement and modelling of the temperature for control purposes. Current ECUs usually incorporate pre-calibrated look-up tables providing the exhaust gas temperature for the open loop control the engine. Although this is a cost-effective solution, ageing, manufacturing discrepancies and sensor bias, can result into significant errors in the exhaust temperature estimation.

Cylinder outlet temperature can be estimated from trapped mass and cylinder pressure data [10]. However, current methods for the online estimation of the trapped mass have important errors: hot-film air mass flow sensors, which are widely employed in automotive applications, can have measurement errors typically in the $5 \%$ range [11] (and up to 20\% [12, 13]) because of ageing and other non-calibrated effects. EGR estimation is even more difficult: the EGR flow estimate based on mean value models is subject to significant errors due to the estimation of different exhaust parameters and semi-empirical corrections, resulting in typical errors of 10\% [14]. Even when using research-grade gas analyzers at test benches, where EGR rate is determined by $\mathrm{CO}_{2}$ balance, errors up to $36 \%$ can be found because of incomplete mixing when using high pressure EGR loops [15]. Model based estimation of the trapped mass through the volumetric efficiency requires from an intake 
temperature sensor (which typically shows a slow time response); in addition, volumetric efficiency must be tabbed by calibration, and can be biased due to 40 engine to engine variability, ageing or off-design operation [16]. Alternative methods, such us $\Delta p$ methodology $[17,18]$, require from unknown parameters, such as in-cylinder temperature at the IVC. Finally, many models for the estimation of the exhaust temperature require the injected fuel mass as an input. Unfortunately, common rail injectors in CI engines have important cylinder-to-cylinder variations in the injected fuel mass caused by minor errors in hole diameter, unavoidable due to manufacturing discrepancies, and by the accumulation of deposits [19, 20].

Cylinder outlet temperature decreases at the exhaust because of both the expansion of the gases and the heat transfer from the gas to the exhaust runner and manifold. This temperature drop plays a key role in the thermal dynamics of the exhaust system, which is of high interest when trying to optimize transient behaviour, since it has a major impact on conventional CI emissions during real driving conditions [21]. The thermal dynamics of a temperature drop in a duct have been studied by many authors, for modelling the exhaust manifold and for catalysts thermal response assessment. Most of the control oriented models represent the heat transfer between the exhaust gases and the walls as a convective process with one or more thermal nodes $[22,23]$. Some of them assume constant wall temperature, usually a similar temperature to that of the coolant, while others include a state for modelling the dynamics of the wall temperature.

The present paper proposes a new model for inlet turbine temperature estimation. The model only uses the in-cylinder pressure signal, together with engine speed and lambda measurements. As it does not need any air mass flow meter nor EGR rate estimation, it shows low sensitivity to sensor errors, ageing and manufacturing discrepancies, and can be used to replace or adapt current exhaust temperature models.

The proposed model was compared with current look-up table models in a four stroke CI engine: fuel injection, EGR, intake pressure and rail pressure variations were performed at different operating points to simulate non-calibrated conditions, and the thermocouple measurement is compared with the model output. Furthermore, the transient response was validated by performing specific transient tests and a WLTP (Worldwide harmonized Light vehicles Test Procedures) cycle.

Regarding the paper structure, next section is aimed to introduce the model formulation. Experimental setup is described in Section 3, where 
details on the test bench, the engine and the employed sensors are provided. A discussion of the results may be found in Section 4, where the model output is compared with other models and temperature measurements, both for steady and transient operation. To conclude, the main contributions of the proposed model are highlighted in the last section.

\section{Model description}

The estimation of the exhaust temperature is done through a three step process:

1. Firstly, it harnesses the in-cylinder pressure resonance modes [24] to estimate the in-cylinder temperature. When using resonance instead of mass flow sensors or speed-density formulation, a non biased measurement can be obtained.

2. Secondly, the expansion of the exhaust gases at the exhaust valves is modelled by a polytropic expansion, with the polytropic coefficient experimentally determined from the pressure trace at the end of the expansion stroke.

3. And, finally, the temperature drop from the cylinder to the turbine inlet is modelled with a nodal model with two temperature nodes: a first node in contact with the engine coolant representing the heat transfer to the liquid-cooled runner, and a second node considering the heat transfer to the surroundings to model the rest of the exhaust manifold. Herein, only convection is considered, by neglecting conduction and radiation.

Next, each one of the calculation steps are detailed.

\section{1: In-cylinder temperature estimation}

In previous works $[25,26,27]$, the authors presented a method capable of predicting in-cylinder trapped mass by relying on the in-cylinder pressure waves. The method detects the most excited frequency in a time-frequency spectrogram to identify the resonance frequency of the first radial mode. Afterwards, by assuming Drapers equation and perfect gas laws, it estimates the trapped mass as:

$$
m=\frac{\gamma p V k_{b}^{2}}{\left(f_{r e s} \pi D\right)^{2}}
$$


where $p$ is the in-cylinder pressure, $V$ is the instantaneous volume, $D$ is the bore, $\gamma$ is the ratio between constant pressure and constant volume heat capacities $\left(c_{p} / c_{v}\right), f_{\text {res }}$ are the detected resonant frequencies, and $k_{b}$ is the Bessel constant for the first radial mode.

The method does not require from calibration when using cylindrical chambers (without bowl) or when the piston is far from the Top Dead Center (TDC). Nevertheless, some calibration procedures were proposed in [28] for engines with bowl and the online implementation was solved in [29], where a compact transformation for mass detection by avoiding time-frequency analysis was presented.

Once trapped mass is known, the in-cylinder temperature $\left(T_{c y l}\right)$ is derived from the perfect gas law:

$$
T_{c y l}=\frac{p V}{m R}
$$

where $m$ is the trapped mass and $R$ is the gas constant $(\approx 286 \mathrm{~J} / \mathrm{KgK}$ for the mixture of burned gases and air [30]).

\section{2: Cylinder outlet temperature estimation}

Exhaust gas expansion at the valves was modelled by a polytropic expansion:

$$
T_{\text {exp }}=k_{1} p^{\frac{k_{2}-1}{k_{2}}}
$$

where the temperature-to-pressure ratio $k_{1}$ and the polytropic coefficient $k_{2}$ are parameters to be identified. In particular, they may be easily fitted just considering that $T_{e x p}=T_{c y l}$ during the end section of the expansion stroke, while the valves are still closed and the combustion is finished. In the present work the polytropic exponent was identified between 100 and 150 CAD after TDC, just before Exhaust Valve Opening (EVO).

After EVO, equation (2) cannot be used because of the existence of mass flow through the exhaust valve and the mass inside the cylinder is unknown; however, if the polytropic coefficient $k_{2}$ is assumed to be reasonably constant, (3) may be still used for inferring the in-cylinder gas temperature. The final engine-out temperature is calculated between 250 and 300 CAD after TDC, where expansion is finished and exhaust valve is not yet closed.

Figure 1 illustrates an expansion where the limits employed to determine the exhaust pressure and temperature are highlighted. Herein $k_{1}$ was 34.6, $k_{2} 1.347, T_{\text {exh }} 827.25 \mathrm{~K}$ and $p_{\text {exh }} 2.24$ bar. Of interest, another pressure 

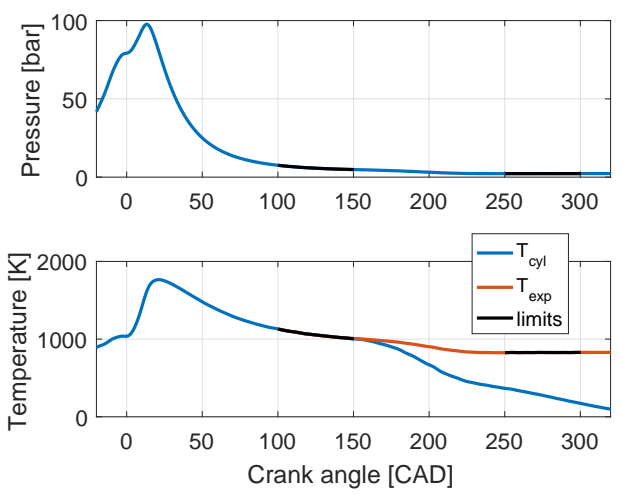

Figure 1: Determined in-cylinder pressure and in-cylinder temperature computed by (2) (blue line) and (3) (red line). Note that the assumptions of (2) are not fulfilled after EVO.

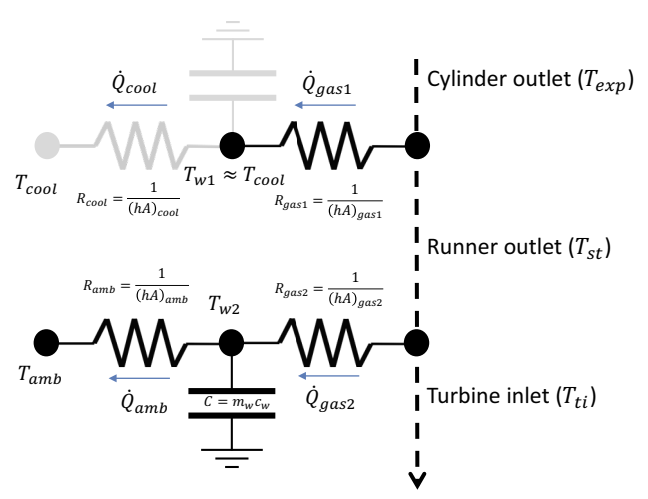

Figure 2: Resistor analogy of the heat transfer nodes in the exhaust manifold

sensor was located at the exhaust runner to detect errors when using these valve flow assumptions and the exhaust pressure discrepancies did not imply important errors at the exhaust temperature estimation.

\section{3: Turbine inlet temperature estimation}

As stated before, the temperature drop along the exhaust has been modelled by a simplified lumped model with two metal nodes [31]: one representing the section of the runner in the cylinder head, which is refrigerated by the engine coolant, and other in contact with the surroundings. Figure 2 aims to represent the heat transfer phenomena in the exhaust manifold by a resistor analogy scheme. 
Herein, some simplifications have been included to reduce the model complexity:

- The heat transfer coefficient to the coolant is much higher than that to the exhaust gases $\left(h_{\text {cool }}>>h_{\text {gas } 1}\right)$, which implies that, when operating in steady state, the temperature of the first node is near to the coolant temperature $\left(T_{w 1} \approx T_{\text {cool }}\right)$. In addition, if the heat transfer to the coolant is assumed to be sufficiently high with regards to the heat capacity of the manifold, dynamics may be neglected and $T_{w 1}(t) \approx$ $T_{\text {cool }}(t)$.

- For the case of $\dot{Q}_{g a s 1}$ and $\dot{Q}_{g a s 2}$, only convection is assumed to be relevant. Solving the partial differential equation of the gas temperature drop [23] yields to:

$$
T_{o}=T_{w}+\left(T_{i}-T_{w}\right) e^{\frac{h A}{\dot{m} c_{p}}}
$$

where $T_{w}$ is $T_{\text {cool }}$ for the first section and $T_{w 2}$ for the second one, $T_{o}$ is the outlet temperature ( $T_{s t}$ or $T_{t i}$ respectively), $T_{i}$ is the inlet temperature ( $T_{\text {exp }}$ or $\left.T_{s t}\right), h$ the convective coefficient, $A$ is the effective area of the pipe wall, $\dot{m}$ is the exhaust mass flow, and $c_{p}$ the constant pressure heat capacity of the gas.

- The exhaust gas convective coefficient only depends on the Reynolds number, as Serrano et al. proposed in [32]:

$$
h \approx k_{h 1} R e^{0.8}=k_{h 1}\left(\frac{4 \dot{m}}{\pi \mu D_{d}}\right)^{0.8}=k_{h 2} \dot{m}^{0.8}
$$

where $R e$ is the Reynolds number, $\mu$ is the dynamic viscosity of the fluid, $D_{d}$ is the diameter at the duct, and $k_{h 1}$ and $k_{h 2}$ are proportional constants.

- The constant pressure heat capacity of the gas is approximated by semi-empirical models, by dividing the mixture in fresh air and burnt products. The correlations proposed by Lapuerta et al. [30] were employed in this work. Figure 3 plots $c_{p}$ as a function of the temperature of the gases and lambda. 


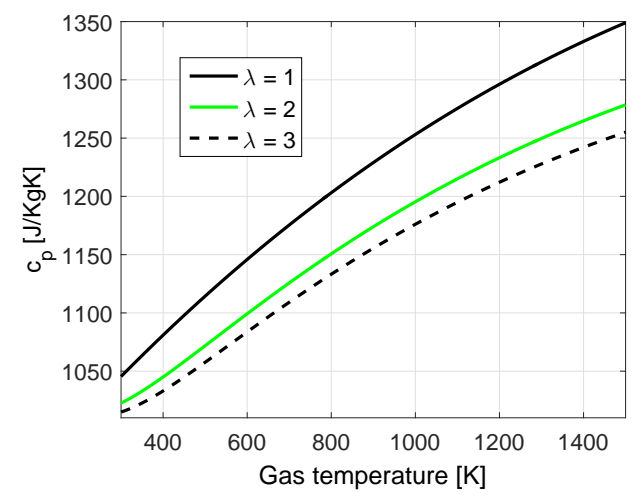

Figure 3: Constant pressure heat capacity of the gas $\left(c_{p}\right)$ as a function of temperature and lambda

- In the test bench, the heat transfer between the exhaust manifold and the surroundings has a constant convective coefficient, as a consequence, the heat transfer can be modelled as:

$$
\dot{Q}_{a m b}=(h A)_{a m b}\left(T_{w 2}-T_{a m b}\right)
$$

So the second node is defined by the following differential equation:

$$
\frac{\mathrm{d} T_{w 2}}{\mathrm{~d} t} m_{w} c_{w}=(h A)_{g a s}\left(T_{g a s}-T_{w 2}\right)+(h A)_{a m b}\left(T_{a m b}-T_{w 2}\right)
$$

where the wall mass $m_{w}$ and the wall heat capacity $c_{w}$ are constant. Thus (7) can be rewritten as:

$$
\frac{\mathrm{d} T_{w 2}}{\mathrm{~d} t}=\dot{m}^{0.8} k_{w g}\left(T_{g a s}-T_{w 2}\right)+k_{a m b}\left(T_{a m b}-T_{w 2}\right)
$$

Including all these simplifications, the final thermal model is defined by the following equations:

$$
\begin{aligned}
T_{s t} & =T_{\text {cool }}+\left(T_{\text {exp }}-T_{\text {cool }}\right) e^{\frac{k_{w 1} \dot{m}^{-0.2}}{c_{p}\left(T_{e x p}, \lambda\right)}} \\
\frac{\mathrm{d} T_{w 2}}{\mathrm{~d} t} & =\dot{m}^{0.8} k_{w g}\left(T_{\text {gas }}-T_{w 2}\right)+k_{a m b}\left(T_{a m b}-T_{w 2}\right) \\
T_{t i} & =T_{w 2}+\left(T_{s t}-T_{w 2}\right) e^{\frac{k_{w 2} \dot{m}^{-0.2}}{c_{p}\left(T_{s t}, \lambda\right)}}
\end{aligned}
$$


Table 1: Main engine characteristics

\begin{tabular}{lcc} 
& Units & Value \\
\hline Cylinders & {$[-]$} & 4 \\
Combustion type & {$[-]$} & CI \\
Unitary displacement & {$[\mathrm{cc}]$} & 374.65 \\
Bore & {$[\mathrm{mm}]$} & 73.5 \\
Compression ratio & {$[-]$} & $17: 1$
\end{tabular}

where $k_{w 1}, k_{w 2}, k_{w g}$ and $k_{a m b}$ are constants that characterize the thermal properties of the exhaust manifold.

Main weakness of the presented thermal model derives from its simplicity. Despite (5) models the effect of the variation of the operating conditions on the convective coefficient of the exhaust gases, such coefficient and the equivalent areas attached to the heat transfer at each one of the nodes may vary as a consequence of the flow conditions; this is specially relevant at (9) due to the significant pressure and temperature pulsation and threedimensional effects. In order to overcome this, a correction coefficient $k_{\text {corr }}$ depending on engine speed $n$ and load $N$ was added to $k_{w 1}$ :

$$
k_{w 1}^{\prime}=k_{w 1} k_{\text {corr }}(n, N)
$$

where $k_{w 1}^{\prime}$ is the coefficient to be used in (9) replacing $k_{w 1}$.

\section{Experimental setup}

A four-stroke diesel engine with 1.5 liters of total displacement was used for the method validation. It is a four-cylinder engine with a turbocharger and a common rail injection system. Table 1 summarizes the main engine characteristics.

The engine was equipped with thermocouples at each runner and at the turbine inlet, and a pressure sensor at the exhaust manifold. The engine-out temperature measurements of all the cylinders were averaged, while the thermocouple located at the turbine inlet was used for calibration and validation purposes.

Thermocouples had $1.5 \mathrm{~mm}$ of diameter as a trade-off between durability and time response. However, as the time response of the employed sensors is expected to be of few seconds, fast temperature variations (i.e. cycleto-cycle) cannot be sensed [33]. For providing a comparison value for the 
validation of the method, thermocouple dynamics were modelled by a first order system, such as:

$$
\frac{T_{\text {mod }}(s)}{T_{t i}(s)}=\frac{K}{1+\tau s}
$$

where $s$ is the Laplace variable, $K$ is the steady state gain and $\tau$ is the time constant. $T_{m o d}$ is then a filtered value of $T_{t i}$ for considering sensor dynamics.

Taking into account the entire process, three dynamic scales can be distinguished:

- The evolution of the temperatures associated to the in-cylinder processes, gas expansion through exhaust valve and heat transfer to the cylinder head (corresponding to $T_{c y l}, T_{\text {exp }}$ and $T_{s t}$ ): they have an instantaneous response and may vary cycle to cycle, so they do not require from any dynamic compensation.

- The manifold wall temperature evolution $\left(T_{w 2}\right.$, and affecting $\left.T_{t i}\right)$ : they are described by equation (7), which has a time bandwidth ranging from few seconds to few minutes.

- The temperature sensor response $\left(T_{m o d}\right)$ : with a typical time response between $100 \mathrm{~ms}$ and 5 sec.

In order to characterize all the required parameters for the model dynamics, three kind of tests were performed.

1. Steady tests: Consisting of 39 operating points over the entire working map, plus 303 operating points performing variations of the control setting on 12 selected operating conditions. Table 2 specifies the injection, EGR, intake pressure and rail pressure variations, as well as the operating conditions of the 12 clusters.

These tests were used to compare the presented model with current methods based on look-up tables, and also for determining the steady state thermal behaviour of the exhaust.

2. Engine speed and load steps: sharp variations in load and engine speed were performed and they were kept constant for two minutes to identify the dynamics of equation (8). The steps levels were defined to reach all the operating conditions at the entire working map. Figure 4 shows the engine speed and the Break Mean Effective Pressure (BMEP) for the transient test performed. Two repetitions were made: one with the EGR valve closed and other with the default EGR valve controls. 


\begin{tabular}{|c|c|c|c|c|c|c|c|c|c|c|}
\hline \multirow[b]{2}{*}{ Cluster } & \multirow{2}{*}{$\begin{array}{l}\mathrm{n} \text { [rpm] } \\
\text { Average }\end{array}$} & \multirow{2}{*}{$\frac{\text { BMEP [bar] }}{\text { Average }}$} & \multicolumn{2}{|c|}{ SOI [CAD-TDC] } & \multicolumn{2}{|c|}{ EGR [\%] } & \multicolumn{2}{|c|}{$\mathrm{p}_{\text {intake }}$} & \multicolumn{2}{|c|}{ prail } \\
\hline & & & $\min$ & $\max$ & $\min$ & $\max$ & $\min$ & $\max$ & $\min$ & $\max$ \\
\hline 1 & 1800 & 9.13 & -5.01 & 10.00 & & & 1.04 & 1.17 & & \\
\hline 2 & 1600 & 15.23 & -5.01 & 10.00 & 0.00 & 16.84 & 1.16 & 1.91 & 744.25 & 1042.84 \\
\hline 3 & 2400 & 9.23 & -5.01 & 10.00 & 0.00 & 42.85 & 1.14 & 2.03 & 947.20 & 1247.35 \\
\hline 4 & 2400 & 15.60 & -2.50 & 10.00 & 0.00 & 17.53 & 1.37 & 2.40 & 1095.29 & 1394.77 \\
\hline 5 & 1600 & 4.89 & -5.01 & 10.00 & 1.54 & 45.87 & 1.02 & 1.11 & 398.41 & 646.83 \\
\hline 6 & 1600 & 13.18 & -5.01 & 10.00 & 1.06 & 22.96 & 1.15 & 1.90 & 695.65 & 994.72 \\
\hline 7 & 2000 & 9.44 & -2.50 & 10.00 & 1.83 & 32.57 & 1.09 & 1.67 & 698.79 & 998.78 \\
\hline 8 & 2800 & 9.68 & -2.50 & 10.00 & 0.00 & 16.89 & 1.24 & 2.11 & 1097.50 & 1397.42 \\
\hline 9 & 2400 & 5.12 & -2.50 & 10.00 & 1.39 & 47.59 & 1.05 & 1.70 & 647.82 & 947.17 \\
\hline 10 & 2400 & 13.36 & -2.50 & 7.49 & 0.00 & 25.40 & 1.46 & 2.45 & 1046.60 & 1345.62 \\
\hline 11 & 2000 & 15.69 & -2.50 & 7.49 & 0.00 & 19.92 & 1.48 & 2.10 & 893.12 & 1192.90 \\
\hline 12 & 2800 & 13.99 & 0.00 & 10.00 & 0.00 & 18.72 & 1.75 & 2.42 & & \\
\hline
\end{tabular}

Table 2: Seetings variations over 12 clusters at diferent operating conditions
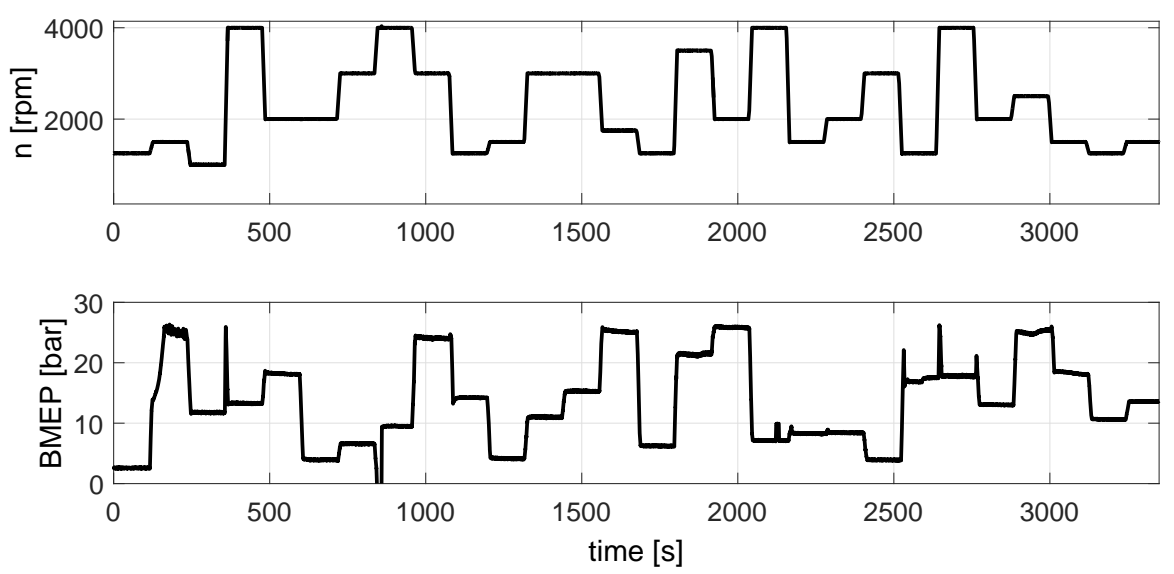

Figure 4: Load and engine speed steps tests used to identify the parameters of the exhaust manifold dynamics 

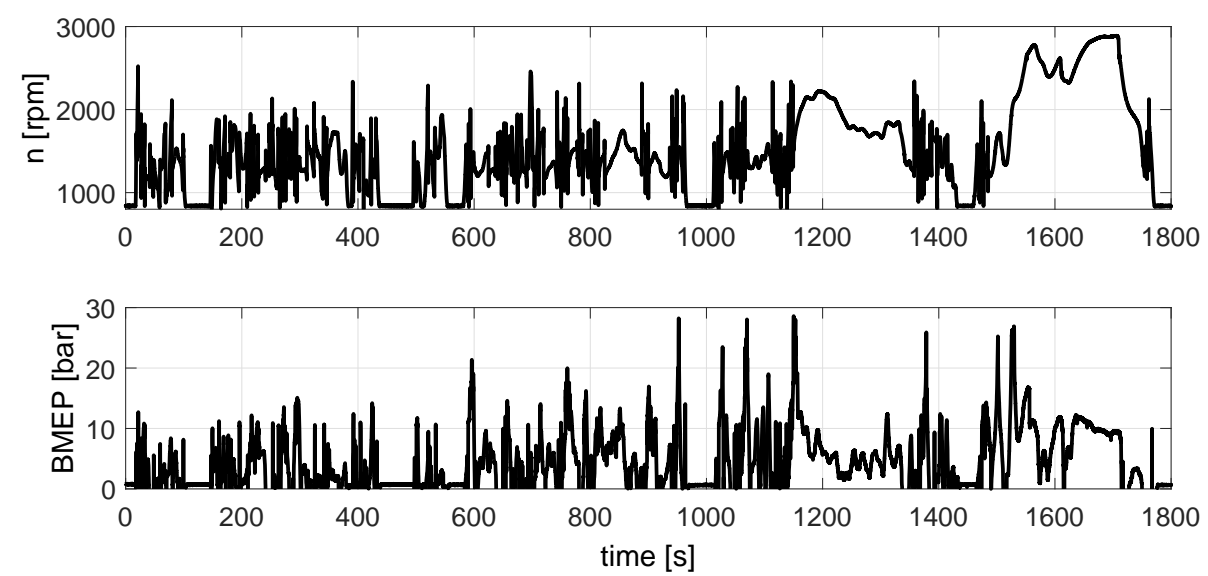

Figure 5: WLTP cycle performed to validate the model under transient conditions

3. WLTP cycle: finally, a cycle was performed to validate the method under realistic operating conditions. Figure 5 shows BMEP and engine speed during the WLTP cycle. Sensor dynamics were identified from this test and found to be consistent with the thermocouple characteristics.

\section{Results and discussion}

\section{Model calibration}

In a first approximation to the model calibration, the heat transfer to the surroundings by convection is neglected in front of the heat exchange in the runner:

$$
\dot{Q}_{a m b}<<\dot{Q}_{g a s 1}
$$

Consequently, while operating in steady conditions, the only temperature drop is caused by the liquid cooled section of the exhaust $\left(T_{t i}=T_{s t}\right)$ and the steady state formulation is reduced to equation (9).

The correction parameter, $k_{\text {corr }}(n, N)$, is then computed for the steady points in order to model the effective area of the equivalent heat exchanger as a function of the operating conditions. A set of 39 tests, ranging from 1000 to $3000 \mathrm{rpm}$ and from 2.5 to 21 bar of BMEP, was used. Figure 6 shows the final calibration results when neglecting the ambient heat exchange. As 


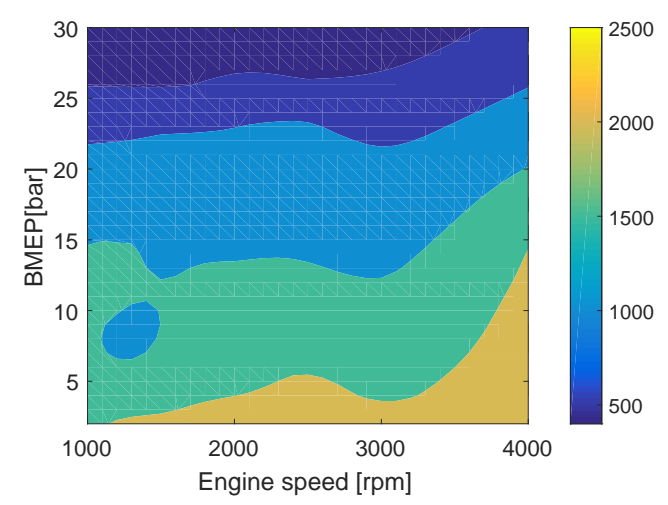

Figure 6: $k_{w 1} k_{c o r r}(n, N)$ table for the pressure based model

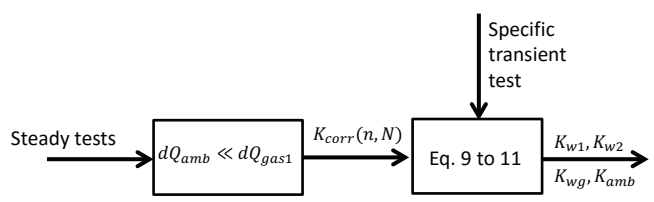

Figure 7: Calibration scheme for the proposed model

expected, as load is increased the efficiency of the cooling process at the runners diminishes, thus resulting in a lower value of $k_{w 1} k_{c o r r}$. The effect of the engine speed is empirically calibrated and deals with discrepancies at the convective coefficient calculation.

Once $k_{\text {corr }}(n, N)$ is obtained by the aforementioned assumptions, the complete model reported at equations (9) to (11) can be fitted by using the specific dynamic test shown in figure 4 . The final identified constants were $1.2163 \times 10^{-4}, 1.316 \times 10^{3}$ and 0.0048 for $k_{w g}, k_{a m b}$ and $k_{w 2}$ respectively (.

The entire calibration procedure is illustrated in figure 7 . It must be noticed that only the set of 39 operating points with the nominal settings and the dynamic test shown in figure 4 (with the EGR valve closed) were used for calibration purposes.

In parallel, a look-up table is also fitted; this kind of modelling method is extensively used in current ECUs and will be used for comparison. The table $\Delta T(n, N)$ maps the difference between the exhaust and the intake manifold temperature as a function of the engine speed and load. A thermocouple 


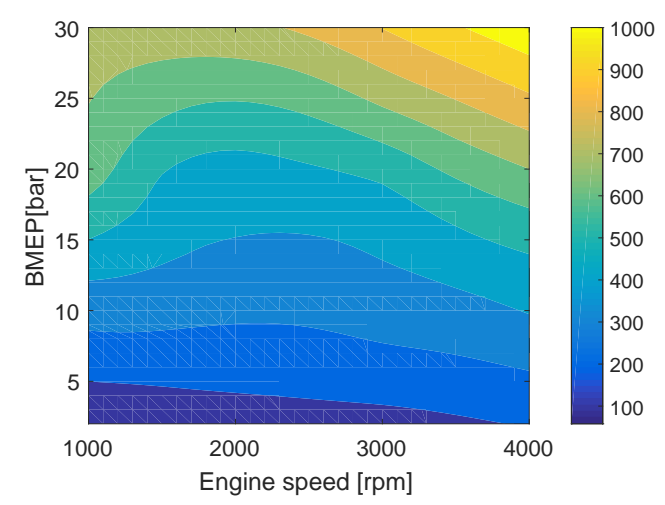

Figure 8: $\Delta T(n, N)$ look-up table for conventional model

was used for measuring intake temperature $T_{i n t}$ and the temperature at the turbine inlet $T_{t i}$ was modelled through:

$$
T_{t i}=T_{\text {int }}+\Delta T(n, N)
$$

Figure 8 shows the final look-up table for this engine. The calibration relative error at the training dataset was $0.1 \%$ for the in-cylinder pressure based model and $0.4 \%$ for the conventional look-up table model.

\section{Steady tests}

As reported before, 342 steady operation tests were available, including tests with nominal settings and varying the injection settings, the EGR rate, the intake pressure and the rail pressure at different operating conditions. The conventional procedure for exhaust temperature estimation, based on look-up tables, was compared with the new in-cylinder pressure based methodology. Note that only 39 tests of the data set were used for the calibration of both models, and the validation dataset includes a wide variation of injection timing, EGR rate, boost pressure and rail pressure.

Figure 9 shows the histogram of the relative errors for both models while table 3 splits the dataset according to the varied control setting. It can be noticed that the pressure based model behaves adequately when combustion settings are changed: the errors at the turbine inlet temperature estimation are lower than $20 \mathrm{~K}$, and the maximum relative error is $7.4 \%$. On the other hand, relaying on a simple look-up table model does not ensure a good estimation when varying control settings: the average temperature error is 35.65 
Table 3: Summary of mean relative errors in the temperature estimation for both models in the validation dataset

\begin{tabular}{l|cccc|c} 
Variations & SOI & EGR & $p_{\text {int }}$ & $p_{\text {rail }}$ & All \\
\hline Pressure based & 2.08 & 2.71 & 2.45 & 2.4 & 2.08 \\
Look-up table & 4.84 & 4.91 & 7.28 & 3.17 & 4.76
\end{tabular}

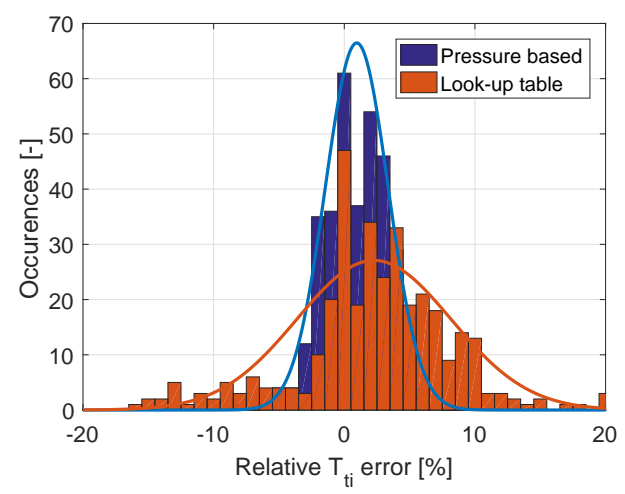

Figure 9: Relative errors at the inlet temperature estimation for both models

$\mathrm{K}$ and the maximum relative error reaches $22.42 \%$. Mean average error for the look-up table approach in the complete dataset is $4.76 \%$, while the same metric for the proposed model is $2.08 \%$. Despite look-up table model could be improved by adding correction factors accounting for the cross-effect of the different disturbances, this would imply additional training tests and a significant calibration work.

\section{Wall temperature dynamics}

The transient test shown in figure 4 was used for the identification of the system dynamics, and later for model dynamic validation. The test, lasting almost one hour, comprised more than 63 thousand engine cycles, which were individually recorded and processed.

As previously reported, the trapped mass was obtained by processing the resonance frequency of the pressure signal. Note that the method developed by Guardiola et al. [25] provides both an estimation of the trapped mass and a quality index for the measurement of each cycle. This facilitates the implementation of filtering and outlier rejection techniques, arising from faulty measurements associated with an insufficient excitation of the pressure resonance. 
Previously to filtering, outliers were detected and removed. The detection was based on detecting abnormally high cycle-to-cycle variations in the mass estimation, or unreasonable values of the volumetric efficiency as calculated on the basis of the original mass estimation $m_{\text {raw }}$. For these cases, the values of the mass estimation and the quality index $I_{q}$ were propagated from the previous cycle. For the case of the mass estimation, a correction was added accounting for the intake pressure $p_{\text {int }}$ evolution. Hence, if measurement at cycle $k$ was determined to be an outlier, its value was modified according to:

$$
\begin{aligned}
m_{\text {raw }}^{k} & =m_{\text {raw }}^{k-1} \frac{p_{\text {int }}^{k}}{p_{\text {int }}^{k-1}} \\
I_{q}^{k} & =I_{q}^{k-1}
\end{aligned}
$$

In a second step, a IIR filter was applied, such us:

$$
m_{\text {filt }}^{k}=(a) m_{\text {filt }}^{k-1}+(1-a) m_{\text {raw }}^{k}
$$

where $m_{\text {filt }}$ is the filtered mass, $m_{\text {raw }}$ is the mass measurement from the pressure signal for the considered cycle $k$, and $a$ the filtering constant.

The filtering constant was chosen to be a function of quality index $I_{q}$, defined as the ratio between the two highest peaks in the pressure spectrum (see [29] for more detailed information). Despite other functions are possible, a linear relation was used here for the sake of simplicity:

$$
a\left(I_{q}\right)=I_{q}
$$

Accordingly, when the quality index is near to 0 (i.e. the resonance is clearly excited and no other peaks appear in the pressure spectrum), the filtered value of the mass is near to the new measurement. Nevertheless, when the quality index is near 1 (i.e. the peak associated with the resonance cannot be easily distinguished from the background noise or other secondary peaks, thus indicating a low quality raw measurement), the filter will reject the measurement provided by the in-cylinder pressure resonance.

Figure 10 shows the results in the trapped mass estimation by the incylinder pressure resonance method over the entire transient $\left(6.3 \times 10^{4}\right.$ pressure cycles). The trapped mass was also computed from lambda and the hot film anemometer $\left(m=m_{\text {air }}\left(1+F_{\text {st }} / \lambda\right)\right)$ to validate the pressure resonance methodology, with a stoichiometric fuel to air ratio $F_{s t}=0.069$. Each dot 


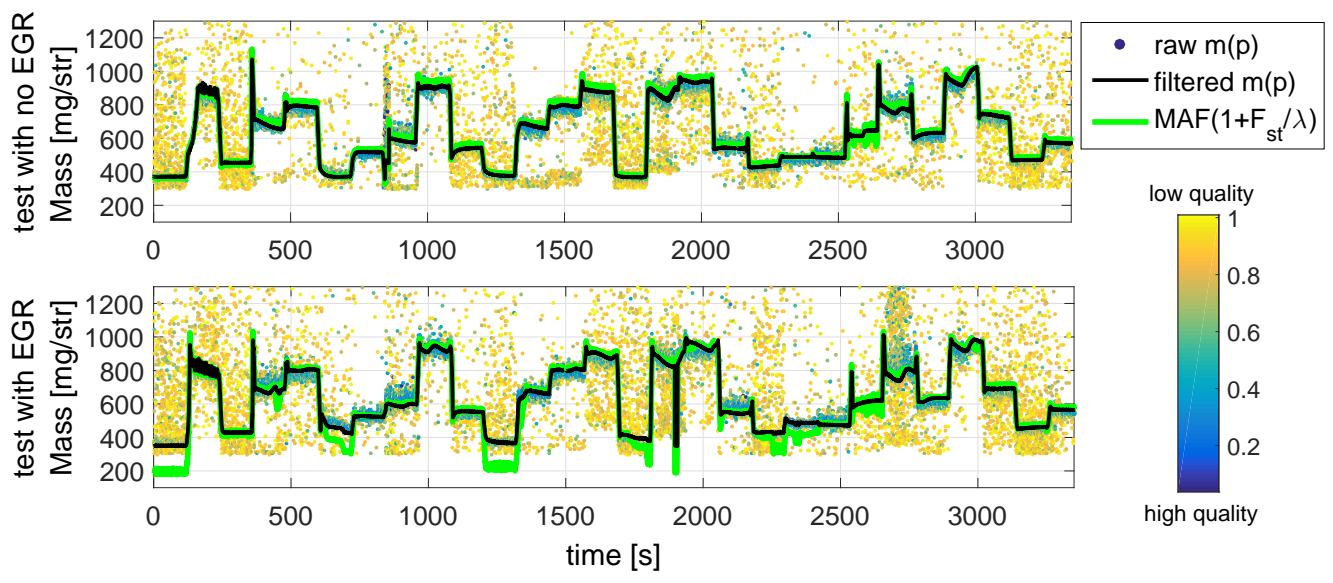

Figure 10: Trapped mass estimation during the transient test without EGR (top) and with EGR (bottom)

in Figure 10 represents a single cycle, and colors indicate the quality index for that cycle according to the figure colorbar (clearer colors indicate low quality).

Top plot in Figure 10 corresponds to a test with no EGR. Thus, the estimation from in-cylinder pressure should be consistent with the values obtained with the lambda sensor and the hot film anemometer; only bias in the sensors and the existence of residuals should create differences between the two methods. It may be clearly appreciated that, once filtered, the measurement provided by the in-cylinder pressure method is coherent with that provided by the lambda sensor and the anemometer. It may also be appreciated that many outliers exist; however, the associated quality index allows to filter them out easily avoiding any effect on the filtered value. There was at least a $15 \%$ of valid cycles for every considered operating condition, and $73.13 \%$ of the pressure cycles were considered valid for the complete test.

Bottom plot in Figure 10 corresponds to a test with nominal EGR. In this case, for some of the operating conditions there is a clear bias between the incylinder pressure method and the lambda and mass flow sensor measurement. This is caused by the recirculated gas, which may not be sensed with the conventional sensors. The in-cylinder pressure method is able to correctly operate on these conditions.

Figure 11 shows the measured temperature $T_{\text {meas }}$ and the main outputs 


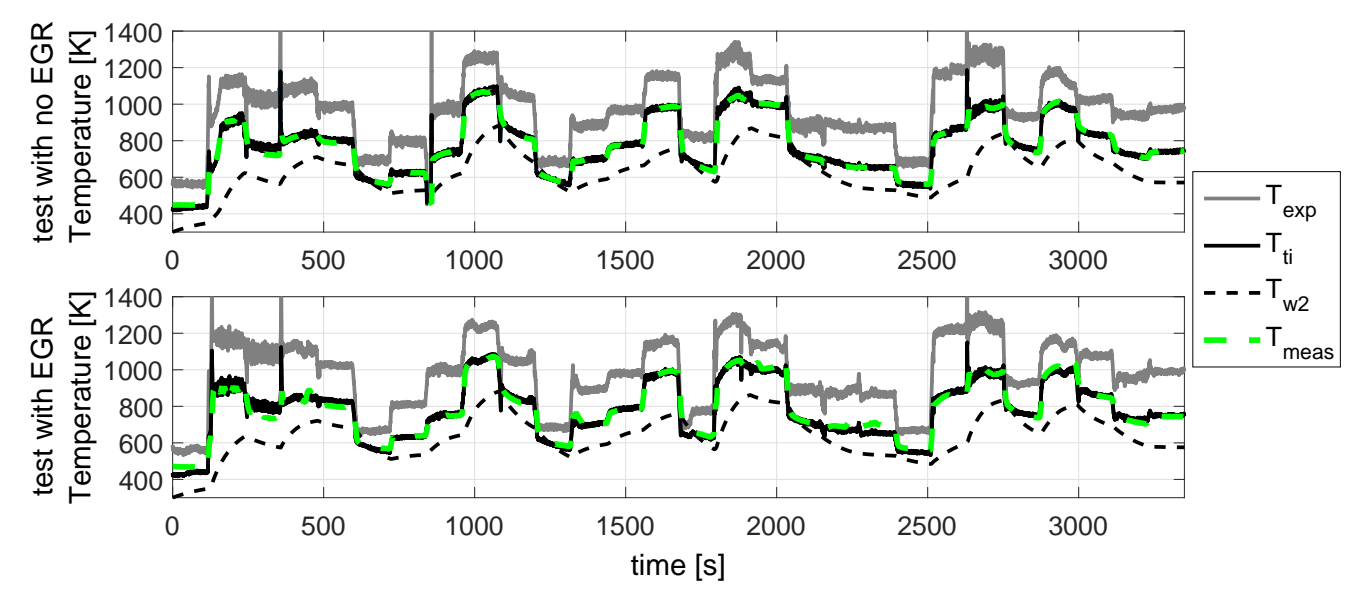

Figure 11: Exhaust temperature outputs of the model and measured value during the transient test without EGR (top) and with EGR (bottom)

of the temperature model: the wall temperature estimation $T_{w 2}$, the engine outlet temperature $T_{\text {exp }}$, and the turbine inlet temperature $T_{t i}$. Again the two tests of Figure 10 are shown. Note that the dynamics of the model adequately fit the thermocouple measurement, and that even for the tests with EGR the bias is kept to a low value. The mean relative error in the turbine inlet temperature estimation for both tests was below $2 \%$. In addition, the model is able to represent the slow response of the wall temperature, which is the responsible of the turbine inlet variation during the sections with constant load.

\section{WLTP cycle}

Finally, the method was validated by performing a WLTP cycle. In order to provide a mean of validation in the trapped mass estimation, the EGR valve was kept closed. This way the trapped mass measurement obtained by the in-cylinder pressure resonance method could be directly compared with the hot film anemometer and lambda sensors.

Figure 12 shows the trapped mass estimation and the measurement provided by the sensors during a section of the WLTP cycle. Again, there is a good agreement between both methods. In addition, the in-cylinder pressure method is free of the spikes exhibited by the calculation based the mass flow and lambda sensors. Note that in a conventional CI engine without variable valve timing the cycle-to-cycle variation of the trapped mass should be 


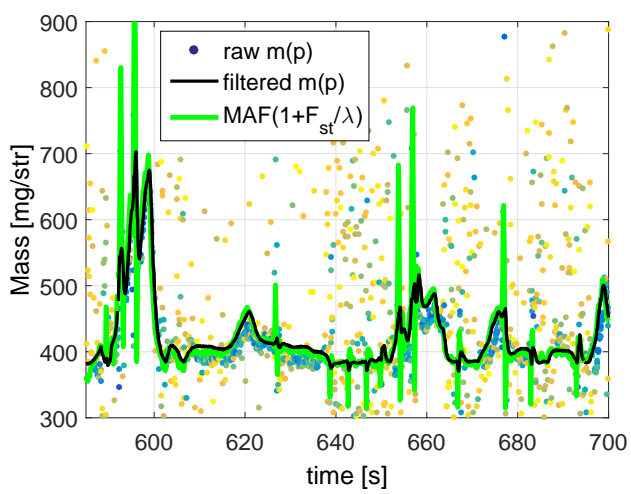

Figure 12: Trapped mass estimation during a section of the WLTP cycle. See Figure 10 for the color bar of the raw measurement

coherent with the air loop dynamics. These spikes in the measurement are then associated with tip in and off, causing the engine to operate with very high or very low fuel-to-air ratio respectively and affecting the accuracy of the lambda based estimation.

In this test, engine dynamics were heavily excited and the temperature sensor response was not sufficient for determine the fast changes in gas temperature. In order to verify the estimation provided by the pressure-based temperature method, the method output must be filtered with the sensor model in (13).

For that, sensor time response was modelled as a first order system with a time response of $3.1 \mathrm{~s}$, which is consistent with the sensor characteristics provided by the manufacturer. Figure 13 shows the model output with and without including sensor dynamics during the same part of the transient cycle. It may be appreciated that the filtered response is coherent with the sensor measurement, and for all the transients in the plot the model behaves in accordance with the sensor.

In addition, the bandwidth of the model is higher, as it is able to represent cycle-to-cycle variations in the engine-out temperature. Note that, opposed to the case of the trapped mass, they are not measurement spikes: engine-out temperature may change from one cycle to the next if fueling is modified in a step-like way, and such abrupt transients may not be sensed with thermocouple technology. In fact, this is an important feature of the model: since it permits a fast estimation of the exhaust gases temperature, it may be used for correcting the thermocouple time response, as in $[34,35]$. 


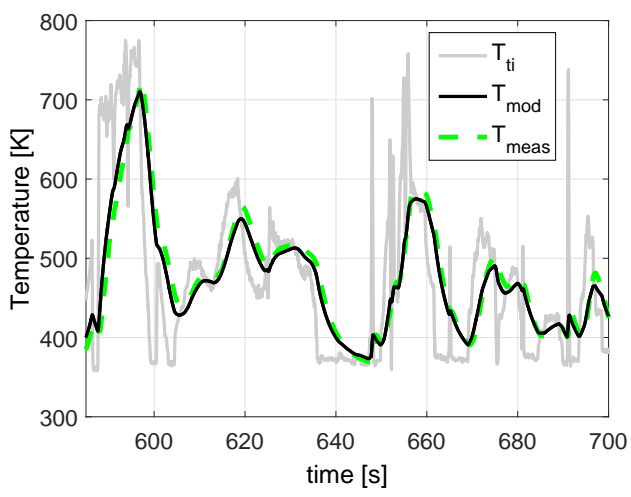

Figure 13: Measured temperature $\left(T_{\text {meas }}\right)$ and model output with $\left(T_{m o d}\right)$ and without $\left(T_{t i}\right)$ considering sensor dynamics during a section of the WLTP cycle

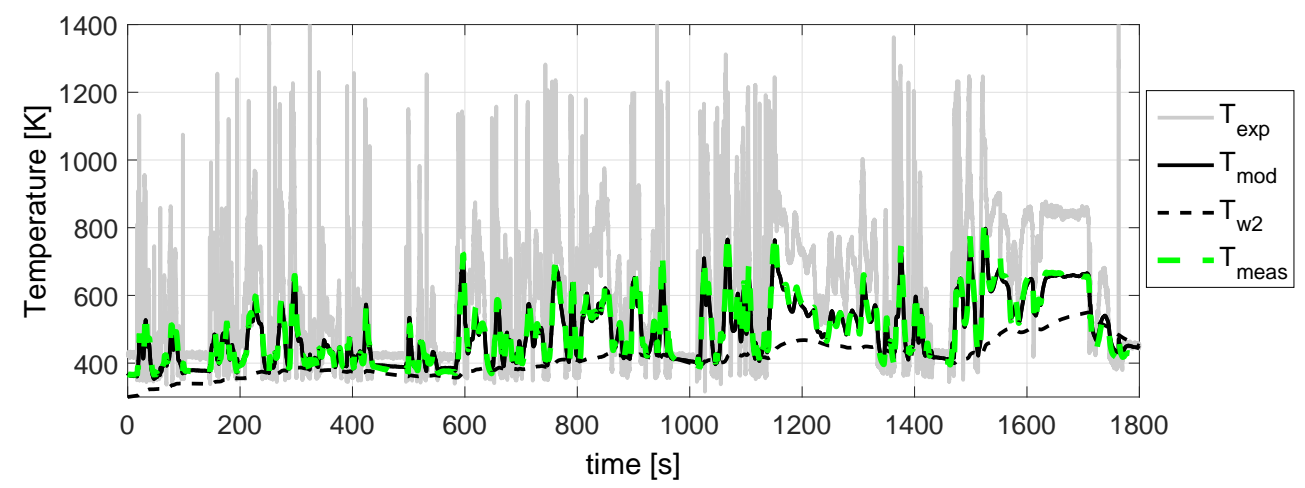

Figure 14: Exhaust temperature estimation during the complete WLTP cycle

The main model results for the complete WLTP cycle are shown in Figure 14, where engine-out gases temperature, wall temperature, final temperature corrected by the sensor dynamics and the measured temperature evolutions are plotted. Once again, the filtered model temperature $T_{\text {mod }}$ agrees with the measurement $T_{\text {meas }}$; average temperature error was $9.62 \mathrm{~K}$, which represent a $1.88 \%$ of mean relative error. In addition, the model was able to represent the progressive heating up of the engine, and its effect in the turbine inlet temperature. Note that a look-up table model is not able to predict this effect unless a thermal model is added. 


\section{Acknowledgements}

This research has been partially financed by the Spanish Ministerio de Economía Competitividad, through project TRA2013-40853-R "Desarrollo de nuevas técnicas de limitación de la pérdida de presión en DPFs para

\section{References}

[1] K. Goudarzi, A. Moosaei, M. Gharaati, Applying artificial neural networks (ANN) to the estimation of thermal contact conductance in the 
exhaust valve of internal combustion engine, Applied Thermal Engineering 87 (2015) 688-697.

[2] J. Macek, O. Vitek, Determination and representation of turbocharger thermodynamic efficiencies, SAE Technical Paper 2016-01-1042.

[3] P. Chen, J. Wang, Control-oriented model for integrated diesel engine and aftertreatment systems thermal management, Control Engineering Practice 22 (1) (2014) 81-93.

[4] J. Schmitt, M. Parmentier, Exhaust temperature predictor : an alternative approach to predictive control applied to diesel aftertreatment, in: IFAC Proceedings Volumes, Vol. 7, 2013, pp. 730-731.

[5] J. Chauvin, G. Corde, N. Petit, P. Rouchon, Motion planning for experimental airpath control of a diesel homogeneous charge-compression ignition engine, Control Engineering Practice 16 (9) (2008) 1081-1091.

[6] J. Zhao, J. Wang, Adaptive observer for joint estimation of oxygen fractions and blend level in biodiesel fueled engines, IEEE Transactions on Control Systems Technology 23 (1) (2015) 80-90.

[7] K. Kar, S. Roberts, R. Stone, M. Oldfield, B. French, Instantaneous exhaust temperature measurements using thermocouple compensation techniques, SAE Technical Paper 2004-01-1418.

[8] S. Eroglu, I. Duman, A. Ergenc, R. Yanarocak, Thermal analysis of heavy duty engine exhaust manifold using CFD, SAE Technical Paper 2016-01-0648.

[9] V. Macián, J. Luján, V. Bermúdez, C. Guardiola, Exhaust pressure pulsation observation from turbocharger instantaneous speed measurement, Measurement Science and Technology 15 (6) (2004) 1185-1194.

[10] M. Mladek, C. H. Onder, A model for the estimation of inducted air mass and the residual gas fraction using cylinder pressure measurements, SAE Technical Paper 2000-01-0958.

[11] J. Arrègle, J. López, C. Guardiola, C. Monin, On board nox prediction in diesel engines: A physical approach, Lecture Notes in Control and Information Sciences 402 (2010) 25-36. 
[12] Z. Liu, C. Wang, An LPV adaptive observer for updating a map applied to an MAF sensor in a diesel engine, Sensors 15 (10) (2015) 27142-27159.

[13] J. Zhao, J. Wang, Engine mass airflow sensor fault detection via an adaptive oxygen fraction observer, in: Proceedings of the American Control Conference, 2014, pp. 1517-1522.

[14] D. Pachner, J. Beran, Comparison of sensor sets for real-time EGR flow estimation, SAE Technical Paper 2016-01-1064.

[15] J. M. Luján, J. Galindo, J. R. Serrano, B. Pla, A methodology to identify the intake charge cylinder-to-cylinder distribution in turbocharged direct injection diesel engines, Measurement Science and Technology 19 (6) (2008) 065401.

[16] J. Heywood, Internal Combustion Engine Fundamentals, McGraw-Hill, Inc., 1988.

[17] J. Worm, An evaluation of several methods for calculating transient trapped air mass with emphasis on the delta p approach, SAE Technical Paper 2005-01-0990.

[18] J. M. Desantes, J. Galindo, C. Guardiola, V. Dolz, Air mass flow estimation in turbocharged diesel engines from in-cylinder pressure measurement, Experimental Thermal and Fluid Science 34 (1) (2010) 37-47.

[19] V. Macián, J. M. Luján, C. Guardiola, A. Perles, A comparison of different methods for fuel delivery unevenness detection in diesel engines, Mechanical Systems and Signal Processing 20 (8) (2006) 2219-2231.

[20] F. Payri, J. M. Luján, C. Guardiola, G. Rizzoni, Injection diagnosis through common-rail pressure measurement, Proceedings of the Institution of Mechanical Engineers, Part D: Journal of Automobile Engineering 220 (3) (2006) 347-357.

[21] M. Lindgren, P. A. Hansson, Effects of transient conditions on exhaust emissions from two non-road diesel engines, Biosystems Engineering 87 (1) (2004) 57-66.

[22] B. Liu, K. Deng, A mean value model for calculating the exhaust temperature drop of an internal combustion engine, International Journal of Vehicle Systems Modelling and Testing 6 (2) (2011) 89-101. 
[23] L. Eriksson, Mean value models for exhaust system temperatures, SAE Technical Paper 2002-01-0374.

[24] C. Draper, The physical effects of detonation in a closed cylindrical chamber, Tech. rep., National Advisory Committee for Aeronautics (1938).

[25] C. Guardiola, B. Pla, D. Blanco-Rodriguez, P. Bares, Cycle by cycle trapped mass estimation for diagnosis and control, SAE Int. J. Engines 7 (3) (2014) 1523-1531.

[26] J. M. Luján, C. Guardiola, B. Pla, P. Bares, Estimation of trapped mass by in-cylinder pressure resonance in HCCI engines, Mechanical Systems and Signal Processing 66-67 (2016) 862-874.

[27] C. Guardiola, V. Triantopoulos, P. Bares, S. Bohac, A. Stefanopoulou, Simultaneous estimation of intake and residual mass using in-cylinder pressure in an engine with negative valve overlap, IFAC-PapersOnLine 49 (11) (2016) 461-468.

[28] A. Broatch, C. Guardiola, P. Bares, F. Denia, Determination of the resonance response in an engine cylinder with a bowl-in-piston geometry by the finite element method for inferring the trapped mass, International Journal of Engine Research 17 (5) (2015) 534-542.

[29] A. Broatch, C. Guardiola, B. Pla, P. Bares, A direct transform for determining the trapped mass on an internal combustion engine based on the in-cylinder pressure resonance phenomenon, Mechanical Systems and Signal Processing 62 (2015) 480-489.

[30] M. Lapuerta, O. Armas, J. J. Hernández, Diagnosis of DI diesel combustion from in-cylinder pressure signal by estimation of mean thermodynamic properties of the gas, Applied Thermal Engineering 19 (5) (1999) $513-529$.

[31] P. Olmeda, V. Dolz, F. J. Arnau, M. A. Reyes-Belmonte, Determination of heat flows inside turbochargers by means of a one dimensional lumped model, Mathematical and Computer Modelling 57 (7-8) (2013) 18471852. 
[32] J. R. Serrano, P. Olmeda, F. J. Arnau, M. A. Reyes-Belmonte, H. Tartoussi, A study on the internal convection in small turbochargers. proposal of heat transfer convective coefficients, Applied Thermal Engineering 89 (2015) 587-599.

[33] B. Sarnes, E. Schrüfer, Determination of the time behaviour of thermocouples for sensor speedup and medium supervision, Proceedings of the Estonian Academy of Sciences: Engineering 13 (4) (2007) 295-309.

[34] B. Fulton, M. Van Nieuwstadt, S. Petrovic, D. Roettger, Exhaust manifold temperature observer model, SAE Technical Paper 2014-01-1155.

[35] C. Guardiola, V. Dolz, B. Pla, J. Mora, Fast estimation of diesel oxidation catalysts inlet gas temperature, Control Engineering Practice 87 (2016) 688-697. 